\title{
Construções contrastivas acontece que e logo eu
}

\section{Contrastive constructions acontece que e logo eu}

\author{
Nilza Barrozo Dias ${ }^{1}$ \\ Jocineia Andrade Ramos Araújo ${ }^{2}$ \\ Priscilla Hoelz Pacheco ${ }^{3}$
}

\begin{abstract}
Resumo: Neste artigo, propomo-nos a analisar as construções contrastivas acontece que e $\operatorname{logo} e u / t u$, não prototípicas, com base em modelos centrados no uso. $\mathrm{O}$ efeito de contraste estabelecido entre os segmentos A e B, em construções prototípicas, resulta de uma quebra de expectativa (não) inferencial, percebida como desigualdade. Utilizamo-nos da proposta de valor semântico da conjunção prototípica mas, de Neves (2011), como exemplar representativo do valor de contraste, para verificar quais relações semânticas são instanciadas pelas construções em foco. Verificaremos, nas amostras selecionadas, os domínios cognitivos chunking (agrupamento) e categorização (BYBEE, 2016). Os dados de acontece que são selecionados em entrevistas da modalidade falada, e logo eu/tu, em amostras de redes sociais e de modalidade falada. Os resultados mostram que acontece que instancia a maior parte das características do conector prototípico mas, enquanto logo eu/tu aponta somente para duas relações semânticas. Ambos instanciam um chunking que nos leva a considerá-los como parte dos conectores de contraste.
\end{abstract}

Palavras-chave: Construções. Contrastivas. Categorização. Acontece que. Logo eu.

Abstract: In this article, we propose to analyze the constructions of contrast acontece que and $\operatorname{logo} \mathrm{eu} / \mathrm{tu}$, from usage-based models perspective. The contrast effect established between segments $\mathrm{A}$ and $\mathrm{B}$, in prototypical constructions, results from a breach of (non) inferential expectations, perceived as inequality. We make use of Neves' (2011) approach regarding the semantic value of the prototypical conjunction mas, in order to verify which semantic relations are instantiated by the constructions in focus. In the selected samples, we verify the cognitive domains chunking and categorization (BYBEE, 2016). The data related to the construction acontece que are selected in interviews of the spoken modality, and the data related to $\operatorname{logo} e u / t u$, in texts on social networks and in speech samples. Results show that acontece que instantiates most of the characteristics of the prototypical connector mas, while $\operatorname{logo}$ eu/tu point only to the semantic relationship resulting from breach of expectations by contrast and by denying inference. The two objects present a chunking that leads us to consider them as part of the connectors of contrast.

Key words: Constructions. Contrast. Categorization. Acontece que. Logo eu.

\footnotetext{
${ }^{1}$ Universidade Federal Fluminense, Instituto de Letras, Programa de Pós-Graduação em Estudos de Linguagem, Niterói, RJ, Brasil. Endereço eletrônico: nilzabarrozodias@id.uff.br.

${ }^{2}$ Universidade Federal Fluminense, Programa de Pós-Graduação em Estudos de Linguagem, Niterói; Instituto Federal de Educação, Ciência e Tecnologia do Rio de Janeiro, São Gonçalo, RJ, Brasil. Endereço eletrônico: jocineiaadd@hotmail.com.

${ }^{3}$ Universidade Federal Fluminense, Programa de Pós-Graduação em Estudos de Linguagem, Niterói, RJ, Brasil. Endereço eletrônico: priscillapacheco@ @id.uff.br.
} 


\section{Introdução}

Objetiva-se analisar as construções contrastivas acontece que e logo eu/tu em amostras de modalidades falada e escrita. Verificaremos como as relações semânticas da conjunção prototípica contrastiva mas se apresentam nas novas relações que emergem dos dados selecionados. Utilizaremos alguns dos processos cognitivos de domínio geral, chunking (agrupamento) e categorização, conforme proposta da Linguística Centrada no Uso de Bybee (2016).

A nossa hipótese considera que acontece que e logo eu/tu funcionam como conectivos textuais de valor semântico contrajuntivo, fazendo parte da rede contrastiva. Tais elementos linguísticos podem conectar sintagmas, orações e enunciados.

Para a verificação da hipótese, objetivamos averiguar quais relações semânticas propostas para a construção mas são instanciadas pelos novos membros e como se alocam na categoria de conectores contrastivos, se mais para o centro ou mais para a periferia.

O texto apresenta a seguinte sequência: abordagem sobre construção e os valores semânticos de tempo e contraste, seguida de considerações acerca da focalização. Prosseguimos com a categorização das construções acontece que e logo eu/tu, seguida de procedimentos metodológicos e análise de dados. Por fim, fazemos as considerações finais e apresentamos as referências bibliográficas.

\section{Construção e o valor semântico de tempo}

A construção é aqui entendida como um pareamento de forma e função. Segundo Goldberg (1995, p. 4): “C é uma construção se e somente se C é um par forma-significado, de tal modo que nenhum aspecto de forma ou de significado seja estritamente previsível a partir de partes componentes de $\mathrm{C}$ ou a partir de outras construções previamente estabelecidas". A relação entre forma e significado realiza-se de maneira bastante integrada, entendendo forma como padrão formal e também como significante, e pode abranger formas presas, itens lexicais e sentenças; já o significado prevê os componentes semântico e pragmático. Assim, toda e qualquer estrutura linguística é construcional, do morfema às orações ou aos enunciados. (BYBEE, 2016; TRAUGOTT; TROUSDALE, 2013).

As construções em estudo expressam valor semântico de tempo na semântica do léxico de origem - verbo acontecer e advérbio $\operatorname{logo}$-, progredindo para o valor semântico de contraste, no sentido de que o segundo segmento marca desigualdade em relação à informação anterior. 
Os eventos, no tempo linguístico, são ordenados a partir do presente da enunciação, o momento da fala, devido ao seu caráter dêitico, podendo se reportar ao que vai acontecer, ao que já aconteceu e ao que está acontecendo (ABRAÇADO, 2020). Lyons (1996) considera o tempo presente como o das verdades atemporais. O presente do indicativo possibilita a intervenção do falante por ser de verdade atemporal; e pode não se reduzir ao momento da fala (MF), mas indicar uma fração de tempo que inclua o momento da fala. $\mathrm{O}$ autor coloca os tempora ao lado dos advérbios, dos pronomes e dos verbos. Assim, o futuro caracteriza-se por indicar um evento posterior a um determinado momento tomado como referência.

Kortmann (1996) investiga, em cento e quarenta polifuncionalidades de conectores adverbiais em línguas europeias e não europeias, relações temporais individuais nas conjunções adverbiais, propondo, num mapa cognitivo, os tempos definido e indefinido. Cabe ao primeiro, o tempo anterior, imediato, simultâneo, de término e o tempo posterior, e, ao segundo, cabe a contingência, que instancia o tempo indefinido. $\mathrm{O}$ autor ressalta que os subordinadores temporais apresentam um espectro de relações temporais que instanciam realizações adjacentes no mapa cognitivo do nó temporal (op.cit., p. 185), sendo que os indicadores de tempo simultâneo e suas variedades são propensas à marcação de relações contrastivas. Também Hilpert (2013) aponta que é bastante recorrente a frequência de tempo simultâneo na geração de contraste em várias línguas investigadas.

No caso de acontece, a perspectiva do falante já se acha bem objetivada no MF, porque o evento está em desenvolvimento ao mesmo tempo em que é referido num espaço atemporal. Dias e Correa (no prelo) apontam que, no século XVI, a estrutura acontece + que, na sua forma origem, é constituída de verbo pleno no presente do indicativo, na oração matriz, com valor lexical de acontecimento/realização de evento, seguido de oração completiva subjetiva, introduzida pela conjunção que, formando uma unidade informacional, uma soldadura, nos termos de Bally (1965). A presença do adjunto adverbial aspectual vezes, no contexto contrastivo, evidencia o aspecto repetitivo de ocorrência do evento. O tempo presente aponta um limite de tempo, mas que poderá ser lido como irrestrito temporalmente, uma atemporalidade (LYONS ,1996).

No caso do advérbio logo, ele faz parte dos circunstanciais de tempo, que são construídos num esquema constituído por uma relação (cronológica), conforme Neves, (1985, p. 486), apontando um evento posterior a um determinado momento tomado como referência. Assim, o logo eu/tu pode ser utilizado para contrastar situações que manifestam primariamente uma comparação entre os eventos, denotando inclusive contraste por negação e 
por negação de inferência e, secundariamente, uma projeção de evento para uma possibilidade de realização futura, mas que não se fará (RAMOS, 2019).

\section{O valor semântico de contraste}

Podemos encontrar a relação semântica de contraste manifestada em modos alternativos de se conectar, sintaticamente, sintagmas e orações/sentenças, tais como nas contrajuntivas e nas concessivas. Tal relação se apoia na desigualdade e ambas as construções em estudo partilham a quebra de expectativa que pode incorporar relação entre os interlocutores, entre conhecimentos compartilhados, etc. Além disso, o contraste por quebra de expectativas, segundo Longhin (2002, p. 118) "não decorre da incompatibilidade semântica entre orações, mas sobretudo de aspectos ligados ao contexto pragmático, que inclui as avaliações, as crenças e as pressuposições do falante".

Para Castilho (2010), o segundo segmento contraria as expectativas geradas no primeiro, funcionando a conjunção mas, prototípica, como um bloqueador de aposição. $\mathrm{O}$ "efeito de contraste resulta de uma quebra de expectativas entre os segmentos A e B, que será percebida como negação, desigualdade, contrariedade, rejeição, não realização de uma relação de causa e efeito ou curso inesperado de evento" (PEZZATI; THOMAZI, 2008, p. 919), sendo que o referido valor contrastivo, segundo Azeredo (2010), pode consistir-se de (i) uma simples oposição de dois conteúdos; ou de (ii) uma quebra de expectativa criada pela primeira proposição. Ele acrescenta também que a conjunção prototípica mas pode ser (iii) focalizadora de circunstâncias e focalizadora contrastiva.

Para Neves (2011, p. 757), as especificações do valor semântico de mas podem ser por contraposição ou por eliminação. Vejamos:

Quadro 1 - Especificações de valores semânticos de mas, conforme Neves (2011)
\begin{tabular}{|l|l|l|}
\hline \multicolumn{2}{|c|}{ 1. CONTRAPOSIÇÃOO } \\
\hline & 1.1 Contraposição em direção oposta \\
\hline & $\begin{array}{l}\text { 1.1.1 Marcando contraste } \\
\text { 1.1.2 Marcando } \\
\text { compensação }\end{array}$ & $\begin{array}{l}\text { Jesus, naquela ocasião, não satisfez a curiosidade dos } \\
\text { discipulos, mas foi à prática: curou o cego. }\end{array}$ \\
\hline $\begin{array}{l}\text { 1.1. 3 Restringindo, por } \\
\text { acréscimo de informação, o } \\
\text { que acaba de ser enunciado }\end{array}$ & $\begin{array}{l}\text { Curto, mas lido com voz clara e sem hesitaços, o discurso } \\
\text { no Congresso arrancou aplausos em várias ocasiões. }\end{array}$ \\
\hline $\begin{array}{l}\text { Casou-se, mas não foi com a Luizinha. } \\
\text { 1.1.4 Negando inferência }\end{array}$ & $\begin{array}{l}\text { O Bar do Porco era velho e fedia: era muquinho de um } \\
\text { português lá onde, por uns mangos fuleiros, a gente matava } \\
\text { a fome, engolindo uma gororoba ruim, preta. Mas eu ia. }\end{array}$ \\
\hline $\begin{array}{l}\text { 1.2 Contraposição na mesma } \\
\text { direção }\end{array}$ & $\begin{array}{l}\text { O sertão, para ele, não é uma coisa, mas principalmente } \\
\text { uma ideia e um sentimento }\end{array}$ \\
\hline
\end{tabular}




\begin{tabular}{|c|c|}
\hline $\begin{array}{l}1.3 \text { Contraposição em direção } \\
\text { independente }\end{array}$ & $\begin{array}{l}\text { O assunto é polêmico, mas o importante é deixar claro que } \\
\text { toda relação estatística precisa ser discutida à luz de } \\
\text { outros conhecimentos }\end{array}$ \\
\hline & 2. ELIMINAÇÃO \\
\hline \multicolumn{2}{|l|}{ 2.1 Eliminação se dá no tempo } \\
\hline $\begin{array}{l}\text { 2.1.1 Negada a subsequência, } \\
\text { nada se põe no lugar }\end{array}$ & $\begin{array}{l}\text { Era um sono de paz que se espalhava pelo corpo e pelo } \\
\text { espírito do velho Noé, mas, súbito, acordou ouvindo um } \\
\text { ruído. }\end{array}$ \\
\hline $\begin{array}{l}\text { 2.1.2 Negada a subsequência, } \\
\text { mas há recolocação }\end{array}$ & $\begin{array}{l}\text { O primeiro contato não traz o prazer esperado. Torres e } \\
\text { pedrinhas magoam- lhes os pés. Mas logo avista, mais } \\
\text { adiante, um trecho de lama, boa, lisa, morna, pegajosa }\end{array}$ \\
\hline \multicolumn{2}{|c|}{ 2.2 Eliminação não se refere a uma relação temporal entre os membros coordenados } \\
\hline $\begin{array}{l}\text { 2.2.1 É negado o que é } \\
\text { enunciado no primeiro } \\
\text { membro }\end{array}$ & Você pensa que sabe, mas não. \\
\hline $\begin{array}{l}2.2 .2 \text { É rejeitada a } \\
\text { oportunidade do primeiro } \\
\text { membro coordenado }\end{array}$ & $\begin{array}{l}\text { Chego a me perguntar mesmo - mas isso não importa } \\
\text { muito nesta conversa. }\end{array}$ \\
\hline
\end{tabular}

Fonte: Elaboração própria a partir de Neves (2011, p. 757-767).

Destacamos que as relações semânticas acima propostas serão aplicadas na investigação das construções acontece que e logo eu/tu.

Neves (2011), ainda, ressalta que a conjunção mas se aplica a início de oração ou início de enunciado, se for por determinações pragmáticas. Entre tais determinações, destacam-se a estratégia de mudança de foco da narrativa e a de progressão temática.

Dias (2020) aponta uma rede construcional em que temos, de um lado, a construção contrastiva com a conjunção paratática prototípica, mas; e temos, na outra posição, as construções contrastivas, menos prototípicas, com acontece $Q U E$, logo $X$, enquanto $Q U E$, agora $X$, já $X$ e até $X$, que apresentam algumas das relações semânticas da rede, decorrentes do contraste, mais a função de focalizador. Tais elementos linguísticos entram como não prototípicos na categorização de conectores contrastivos. E tanto o verbo quanto o advérbio acima apontados instanciam uma noção de tempo em suas bases, o que nos leva a uma reanálise da noção de tempo em valor de contraste.

\section{A focalização}

A focalização constitui uma das estratégias utilizadas pelo falante para fortalecer sua argumentação e, assim, atingir seus propósitos comunicativos. O falante salienta, focaliza aquilo que ele considera importante e principal dentre toda a informação que está sendo veiculada e possa acrescentar algo ao conhecimento pragmático do ouvinte (DIK, 1981). De acordo com Halliday (1994, p. 204), “foco é um tipo de ênfase por meio da qual o falante 
salienta parte (que pode ser o todo) de um bloco de informação como a que ele deseja que seja interpretada como informativa".

O foco ainda pode apresentar subclassificações. Ele pode ser classificado em foco amplo e foco estreito a depender da porção textual a ser focalizada. O primeiro pode ser dividido entre foco de predicado e foco sentencial. A estrutura de foco de predicado seria a não marcada, no qual os argumentos seriam tópico e comentário, enquanto o foco sentencial corresponde à focalização de uma sentença inteira. Já o segundo, o foco estreito, ocorre quando um único argumento da sentença é focalizado, chamado de foco argumental.

Além da porção textual, há ainda teorias que classificam o foco com base na função que exerce no discurso. Nesse caso, os tipos de foco mais difundidos são o informacional e o contrastivo (ou identificacional) (DIK, 1981; LAMBRECHT, 1994). Foco informacional é aquele que insere informação não compartilhada/nova entre os interlocutores ou que o falante tem o propósito de apresentar como informativa em relação às suas crenças. Já o foco contrastivo visa a transmitir algum tipo de contraste/oposição em relação a um fato já pressuposto pelo interlocutor. Nesse caso, a focalização pode apontar informação dada/compartilhada, mas que o falante ache importante realçar, num conjunto de entidades possíveis, no ato da comunicação, com a intenção de comparar, contrapor informação presente em contexto anterior (LEITE DE OLIVEIRA, 2017; PACHECO, 2020).

\section{Categorização das construções em estudo}

"Categorizar é agrupar entidades (objetos, ideias, ações, etc) por semelhança" (LIMA 2010). Tal processo ajuda na demanda humana, porque simplifica a interação do indivíduo com o ambiente, podendo a informação ser facilitada no que diz respeito ao armazenamento e sua recuperação (ROSCH, 1978). As novas construções são definidas como mais ou menos periféricas em relação ao protótipo central, apresentando graus de compartilhamento (TAYLOR, 1995; BYBEE, 2016).

Para Bybee (2016, p. 138), “a categorização se dá por comparação local de itens em vários aspectos quanto à frequência de ocorrência. Isso significa que itens formam relações estreitas, locais, sempre que possível”.

$\mathrm{Na}$ categorização, a autora aborda a esquematicidade que aponta para a abstração semântica de um grupo geral de construções, procedural ou de conteúdo. O esquema é uma generalização taxonômica de categorias linguísticas (ou não) que aponta a captura de padrões gerais através de uma série de construções específicas, as microconstruções. Ele é rotinizado, entrenched (enraizado), como resultado de modelos da experiência (LANGACKER, 1993; 
BYBEE, 2016; CROFT, 2001), sendo as estruturas simbólicas construídas dentro do esquema e apresentando slots (espaços) que podem ser inteiramente abstratos (SVO) ou parcialmente esquemáticos. Linguisticamente são grupos semanticamente gerais e abstratos de construções e, segundo Traugott e Trousdale (2013), tais abstrações se fazem por uma série de construções que são percebidas intimamente relacionadas umas às outras pelo falante. Os graus de esquematicidade, segundo os autores, estão relacionados aos níveis de generalidade e especificidade.

O esquema da construção contrastiva é uma generalização taxonômica das categorias que o compõem; são abstrações estabelecidas a partir de conjuntos de construções que são percebidas pelos usuários como intimamente relacionadas umas às outras na rede construcional contrastiva. As construções menos prototípicas em foco apresentam relações com o conjunto, representando a expansão da rede de contraste.

Na construção acontece que, temos a mudança de categoria de verbo para a função de novo membro da categoria de conector textual contrastivo que focaliza e faz ressalva da informação contida em B. É oriundo da categoria de verbo de acontecimento que migra para o grupo dos contrastivos, no esquema verbo $X$ (DIAS e CORREA, no prelo).

A construção logo eu/tu também se apresenta como um novo membro da categoria de contraste. $\mathrm{O}$ advérbio temporal logo migra para a categoria de conectores contrastivos não prototípicos, formando um chunk (agrupamento) com $e u$ ou $t u$. Temos um evento A, seguido de intervalo de tempo, mais um evento $B$, em que se observa o valor semântico de contraposição por contraste ou por negação de quebra de expectativa. A cena evocada pelo falante diz respeito a frames compartilhados pelos usuários, recheada de metáforas conceptuais. No evento B, encontramos um contraste não explicitado formalmente, mas identificado pelo processo inferencial, com o conector contrastivo logo eu/tu focalizando a justificativa da contra-argumentação (RAMOS, 2019). A autora afirma que a construção se comporta de modo semelhante aos advérbios denominados focalizadores (ILARI, 1992; CASTILHO, 2010) por dar destaque a uma informação que o falante julga importante para o conhecimento pragmático do ouvinte.

\section{Procedimentos metodológicos}

Como já exposto, temos como objetivo neste trabalho investigar os usos de acontece que e logo eu/tu no português brasileiro contemporâneo, utilizando a classificação de valores semânticos de Neves (2011) para o mas, aplicada aos nossos objetos, a fim de verificarmos como se comportam os novos membros na categoria de contraste. Lembramos que a língua é 
um grande inventário de construções, marcada por uma gramática emergente. (GOLDBERG, 1995, 2006; CROFT, 2001; BYBEE, 2016; TRAUGOTT; TROUSDALE, 2013).

Hopper e Traugott (2003) reconhecem que uma dada sincronia já aponta evidências significativas de mudança no uso da língua, o que dá suporte à nossa pesquisa, embora assinalem que a mudança linguística deva ser comprovada mais efetivamente por meio de estudos diacrônicos ${ }^{4}$.

A seguir, traçamos um paralelo da construção acontece que com os valores semânticos identificados no uso, com base em uma adaptação da proposta de Neves (2011).

Quadro 2 - Valores semânticos de acontece que, a partir dos estudos de Neves (2011) para o mas

\begin{tabular}{|c|l|}
\hline \multicolumn{2}{|c|}{ VALORES SEMÂNTICOS DE ACONTECE QUE NO PORTUGUES } \\
CONTEMPORÂNEO \\
\hline \multirow{4}{*}{$\begin{array}{c}\text { COM CONTRASTE } \\
+\end{array}$} & Contraste por oposição \\
\cline { 2 - 2 } FOCALIZAÇÃO & Contraste por parcialidade \\
\cline { 2 - 2 } & Contraste por eliminação do trecho anterior \\
\cline { 2 - 2 } & Contraste por negação de inferência \\
\cline { 2 - 2 } & Contraste por direção independente \\
\cline { 2 - 2 } & Contraste por marcação de compensação \\
\hline
\end{tabular}

Fonte: Elaboração própria, com base em Pacheco (2020).

Ressalta-se que nessa análise tanto propriedades formais quanto semânticas foram consideradas, tomando-se, assim, o contexto de uso como amplamente construído, conforme defendem Traugott e Trousdale (2013).

Elegemos o site Memória Roda Viva ${ }^{5}$ como nosso banco de dados. O site reúne entrevistas transcritas do programa de televisão Roda Viva, exibido pela TV Cultura. Analisamos 500 entrevistas, sendo encontrado um total de 160 ocorrências de acontece que. Entretanto, nove dados foram descartados pelo fato de o falante ser estrangeiro e por haver muitas interrupções que impediram o desenvolvimento do texto, o que totaliza 151 ocorrências. Desses 151, entretanto, dezoito não apresentam valor contrastivo e, por essa razão, para este trabalho, o corpus é constituído por 133 ocorrências.

Já em relação ao segundo objeto, a construção logo eu/tu, percebemos que, em todos os dados, há presença constante da função focalizadora. A seguir, traçamos um paralelo da construção com os valores semânticos identificados no uso, com base em Neves (2011).

\footnotetext{
${ }^{4}$ Hilpert (2013), por exemplo, buscou identificar mudança linguística em um estudo sincrônico.

${ }^{5}$ Disponível em: http://www.rodaviva.fapesp.br/.
} 
Quadro 3 - Valores semânticos de logo eu/tu, a partir dos estudos de Neves (2011) para o mas.

\begin{tabular}{|c|l|}
\hline \multicolumn{2}{|c|}{ VALORES SEMÂNTICOS DE $L O G O$ EU/TU NO PORTUGUÊS } \\
CONTEMPORANEO \\
\hline $\begin{array}{c}\text { COM CONTRASTE } \\
+\end{array}$ & Contraste por negação de inferência \\
\cline { 2 - 2 } FOCALIZAÇÃO & Contraste por oposição \\
\hline
\end{tabular}

Fonte: Elaboração própria, com base em Ramos (2020).

Nomeamos as redes sociais para investigarmos a construção logo eu/tu e identificamos dois segmentos de um enunciado, marcando desigualdade, sendo o primeiro constituído geralmente de verbos volitivos e modalizadores expressos, e o segundo constituído de uma quebra de expectativa que leva a uma negação do que foi dito anteriormente, num evento não explícito formalmente, mas que é inferido, com o $\log o \mathrm{eu} / \mathrm{tu}$ funcionando como focalizador da justificativa contra-argumentativa. Na construção, podemos observar que $e u$ e $t u$ são o ponto de apoio da irradiação do contraste. A seguir, a representação da construção $\operatorname{logo} e u / t u$ :

[VONTADE, DESEJO verbo volitivo/modalizador; orações optativa ][CONTRASTE FOCALIZADOR inferencial [ MAS NÃo CONSEGUIU LOGO X + ORAÇÃO OU SINTGMA NOMINAL]]

Para a análise da construção acima, iniciamos as buscas a partir do item lexical logo. Excluímos os dados que apresentavam valor temporal ou conclusivo e focamos os nossos esforços na construção contrastiva. Investigamos as ocorrências no corpus PorUs (www.uff.br/porus), e em redes sociais (Facebook, instagram, twitter), com o auxílio da ferramenta de busca Google, perfazendo um total de 97 ocorrências. Por meio dessa triagem, os dados analisados foram aqueles em que constavam os preenchimentos de slot (espaço) X, posposto ao item $\operatorname{logo}$, que pode ser preenchido por $\mathrm{SN}$ (pronomes pessoais e nome próprio) e por SAdv (ontem, hoje e agora). Selecionamos para este trabalho o logo eu/tu. Fizemos, manualmente, a contagem de 75 ocorrências de logo eu e 4 ocorrências de logo tu.

É importante destacar que a análise envolve ainda o entendimento de como os processos cognitivos de domínio geral são incorporados pelo falante para a compreensão e uso das características categoriais de determinada construção linguística que se aloca em outro nó da rede, por analogia com as funções daquela outra construção, absorvendo características que colocam as construções em estudo no centro ou na periferia dessa nova função, conforme apontado por Bybee (2016). Todo o processo inclui a percepção de processos metonímicos que possibilitam a absorção de significado a partir de contágio, isto é, por repetição e estocagem de elementos frequentes, além de identificar o papel das inferências 
sugeridas na situação comunicativa (BYBEE, 2016; TRAUGOTT; TROUSDALE, 2013). Destacamos o chunking e a categorização para a análise das amostras.

\section{Análise de dados}

A análise das ocorrências será dividida em duas partes: a primeira compreende a proposta acerca de acontece que e a segunda compreende as ocorrências com logo eu/tu. Cada uma detém uma representação específica, conforme suas características relacionadas à forma que possui e à função que exerce. As construções apresentam valor temporal no domínio fonte, o valor semântico de contraste no plano meta, além da função pragmática focalizadora.

A fim de atingir o propósito estabelecido, pretende-se verificar quais relações semânticas do mas prototípico, conforme Quadro 1, são encontradas nas construções apontadas e como o falante adequa as relações semânticas das construções em foco para o enquadramento na categoria de contraste. Além disso, iniciaremos a análise de processos de domínio geral, primeiramente com chunking (agrupamento) ao consideramos que, em acontece que e logo eu/tu, o falante pratica e repete sequências de palavras, passando a embalá-las juntas e acessá-las como uma unidade que opera na formação de unidades mais complexas. É a interação de chunking com categorização que permite ao falante perceber, em graus variados, a analisabilidade e a composicionalidade das sequências convencionalizadas. Nas construções, as partes que as compõem podem ser identificadas, mas o significado só se faz acessível quando se vê o conjunto, o que as coloca como mais composicionais. $\mathrm{Na}$ sequência, verificaremos os resultados obtidos e as características dos novos membros como chunks na categoria de contraste.

\section{A construção acontece que}

Mostraremos inicialmente o papel de acontece que e de que modo os usuários da língua, na tentativa de serem mais precisos na interação, utilizam-se da construção no português contemporâneo. Vejamos o primeiro exemplo:

(01) Alberto Goldman: Nós passamos oito anos sendo violentamente agredidos pela oposição na época (...). Nós "entregávamos o Brasil ao imperialismo"; éramos "vendidos ao capital financeiro internacional, nacional”; éramos “os eticamente condenáveis". Tudo o que se fazia, qualquer coisa que acontecia era "um bando de ladrão" (...). E nós perdemos. Muitos companheiros perderam a eleição porque muitos perderam milhares e milhares de votos. Isso 
estava tudo engasgado. Acontece que, infelizmente, nesse segundo turno, parece que essa coisa explodiu, emergiu toda. (Entrevista com Alberto Goldman, em 12/09/2005)

No trecho acima, Alberto Goldman coloca como engasgado o episódio em que muitos companheiros seus de partido perderam a eleição. Já na sentença introduzida pela construção acontece que, o político aponta que essa situação, até então engasgada, explodiu e emergiu. Explodir e emergir não são verbos diretamente antônimos a engasgar. No entanto, considerando o sentido pretendido pelo falante, fica clara a oposição entre os usos das palavras e, ainda, mais especificamente, entre as ideias pretendidas: o que está engasgado está preso, está no campo do não-dito e, consequentemente, não está sendo trazido à tona. Assim, é produzido no trecho contraste por oposição de ideias.

Vejamos o próximo exemplo:

(02) Julio Abramczyk: Doutor Adib, o senhor falou em equipamentos e há um paradoxo dentro da medicina, que quanto mais ela avança tecnologicamente mais cara ela fica. (...) Por que na medicina os equipamentos melhoram e encarecem?

Adib Jatene: Não, na verdade eles também baixam de preço. Acontece que eles não têm a economia de escala. (Entrevista com Adib Jatene, em 12/01/1998)

O exemplo (02) trata do elevado preço dos equipamentos utilizados na medicina. $\mathrm{O}$ entrevistado argumenta que esses equipamentos baixam de preço, assim como os outros citados. Entretanto, Jatene menciona, no trecho introduzido por acontece que, que diferentemente dos demais equipamentos tecnológicos, aqueles utilizados na medicina não possuem economia de escala, o que impacta diretamente nos preços.

Nesse sentido, a sentença introduzida pela construção não nega completamente o que foi dito antes ("eles também baixam de preço"): ela contrasta parcialmente o conteúdo, acrescentando uma informação importante que influencia de modo significativo a queda ou o aumento de preços de certos produtos. Cabe destacar que esse contraste parcial, em direção oposta, e que restringe, por acréscimo de informação, o que acaba de ser enunciado, é um dos valores prototípicos do mas, apontados por Neves (2011). Outro valor prototípico ressaltado por Neves (2011) é o de eliminação, conforme a seguir:

(03) Luciano Suassuna: Mas, nessa questão, qual seria a diferença entre o que foi dito pelos líderes do MST e o que foi dito pelo presidente da Associação dos Magistrados Brasileiros ou 
o ministro Sepúlveda Pertence, de que as pessoas tinham... Nenhum juiz iria condená-los por causa desse furto famélico, uma expressão assim.

Milton Seligman: Acontece que não é furto famélico que nós estamos vendo no caso nordestino. (Entrevista com Milton Seligman, em 11/5/1998)

No trecho (03), o entrevistador Luciano Suassuna questiona o entrevistado sobre supostos furtos famélicos realizados pelo Movimento dos Trabalhadores Rurais Sem Terra (MST), isto é, furtos de alimento para o próprio sustento. Milton Seligman, à época presidente do Instituto Nacional de Colonização e Reforma Agrária (Incra), é enfático ao desconsiderar a fala de Suassuna, negando que o caso fosse de furto famélico. Desse modo, Seligman faz com que o acontece que introduza uma negação completa da fala do entrevistador (não é furto famélico), que desconsidera e, portanto, elimina, conforme Neves (2011), o que foi pontuado.

Já em relação ao valor de negação de inferência, vejamos o exemplo a seguir:

(04) Mônica Teixeira: Agora, doutor Jatene, deixa perguntar uma coisa? O senhor, quando está falando em dinheiro da saúde, sempre fala nos hospitais, o senhor acha que o problema da saúde no Brasil é pagar em dia os hospitais ou pagar melhor os hospitais?

Adib Jatene: (...) O que nós gastamos com atendimento médico hospitalar é menos da metade do orçamento, acontece que o que mais tem visibilidade na imprensa é o atendimento médico hospitalar, por isso eu falo hospital. (Entrevista com Adib Jatene, em 1998)

No exemplo acima, é abordada a questão da aplicação do dinheiro do Ministério da Saúde. Quando o ex-ministro diz que "o que nós gastamos com atendimento médico hospitalar é menos da metade do orçamento", infere-se que mais atenção deveria ser dispensada aos outros gastos que consomem mais do orçamento público. Entretanto, é sobre o atendimento médico hospitalar que a imprensa gosta de falar. Desse modo, o acontece que introduz a quebra de expectativa, negando a inferência de que outros itens do orçamento deveriam receber mais atenção, uma vez que é o atendimento médico hospitalar que ocupa a maior parte dos interesses da mídia.

O quinto valor semântico encontrado para o acontece que é o de contraste por direção independente. Vejamos o exemplo (05): 
(05) José Alencar: Há estados do Brasil, que você mesmo conhece, em que da receita líquida, $75 \%$ vai para folha de pagamento. Desses $75 \%$, $41 \%$ é para inativos. Então, veja bem, a reforma da Previdência não é ideal e nem é vontade do presidente Lula, é exigência do Brasil. Paulo Markun: E ainda assim dá a impressão de que os setores que são contra a reforma da Previdência (...) estão muito mais ativos e atuantes do que supostamente a grande maioria, que deve ser a favor da reforma. O senhor não acha?

José Alencar: Não, tudo bem, mas acontece que a reforma é posta como assinatura dos 27 governadores (...). (Entrevista com José Alencar, em 16/6/2003)

Todo o trecho anterior trata da questão da reforma da previdência, ainda no ano de 2003. Ao longo da entrevista, o ex-vice-presidente da República, José Alencar, deixa claro seu posicionamento a favor da reforma. O entrevistador, por sua vez, menciona que alguns setores da sociedade estão mais atuantes contra a reforma do que a suposta maioria que seria a favor. Ao responder, em uma tentativa de mudar o subtópico do assunto, Alencar introduz o acontece que, antecedido por um mas e por um não, pontuando que a reforma é uma necessidade de todos os governadores do Brasil.

O mas acontece que destaca que, na verdade, não importa que haja pessoas contra a reforma, o que importa é que todos os governadores são a favor, como tentativa de equilibrar as contas dos estados brasileiros, realizando um contraste por direção independente, que também é um dos valores prototípicos de mas. Assim, José Alencar escolhe como argumento superior e, portanto, mais relevante, a posição dos governadores.

O sexto e último valor semântico encontrado para o acontece que é o de marcação de compensação, conforme vemos no exemplo a seguir:

(06) Luiz Carlos Bresser Pereira: Se nós examinarmos o que aconteceu no Brasil nos últimos 25 anos (...), nós vemos que, em termos de renda per capita, cresceu pouquíssimo, cresceu 8\% a renda per capita. Nos anos 1970, crescia 8\% em dois, máximo três anos. Agora, vinte anos entre 1980 e 2000, 8\%. Aí, eu me perguntei: mas, ao mesmo tempo, acontece que os índices sociais no Brasil melhoraram muito. O analfabetismo caiu de $31 \%$ para $15 \%$ da população. A mortalidade infantil caiu de trinta por mil, para 16 por mil.

Em um primeiro momento, Bresser Pereira pontua que a renda per capita no Brasil cresceu bem menos do que deveria nos últimos 25 anos, entretanto, indica que, em contrapartida, os índices sociais melhoraram muito. Assim, o acontece que, que introduz uma 
quebra de expectativa, apontando para um detalhe que faz toda a diferença na construção da argumentação. Esse detalhe é considerado como uma ressalva que marca a compensação entre o positivo e o negativo. Cabe ressaltar que apontar para um aspecto positivo é diferente do que foi predominantemente encontrado nas análises dos nossos dados. De modo geral, o acontece que é utilizado para introduzir noção de contraste por ressalva negativa.

Diante do exposto, no que se refere à persistência da noção temporal, podemos dizer que o acontece que é utilizado para introduzir uma ruptura entre o evento que o antecede e o evento que o sucede. Ambos os eventos se projetam no tempo presente, uma vez que possuem valor de verdade universal, atemporal. O valor de verdade universal é relevante no sentido de que o acontece que está sendo utilizado com força argumentativa. Assim, com o acontece que, os falantes se utilizam do presente atemporal para posicionar suas declarações em um patamar sem possível refutação.

\section{A construção $\log o$ eu $/$ tu}

Após discussão sobre o acontece que, nesta seção, mostraremos o papel de logo eu/tu e de que modo os usuários da língua, na tentativa de serem mais precisos na interação, utilizam-se da construção no português contemporâneo. É possível notar que a construção logo eu/tu, assim como a construção acontece que, revela um significado contrastivo com resquícios do sentido temporal.

A seguir, seguem três exemplos, a fim de verificar a análise descrita:

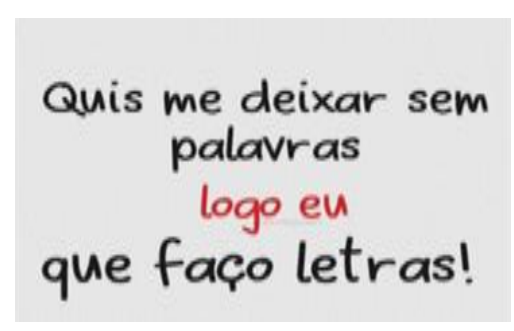

(Rede Social)

No exemplo (07), a construção com verbo volitivo querer no primeiro segmento, "Quis me deixar sem palavras", mostra que o interlocutor você, de referência indefinida, ansiava por deixar o falante sem palavras. O desejo expresso no primeiro segmento gera uma expectativa, que é quebrada quando se percebe que houve, de fato, uma negação inferida do que foi expresso: mas você não conseguiu me deixar sem palavras, o que configura, do ponto de vista das relações semânticas, uma desigualdade entre os segmentos que leva a uma leitura 
de contraste e negação. O logo $e u$ focaliza a justificativa de uma contra- argumentação: $o$ falante faz letras, sendo que o pronome eu aponta a ironia e o espanto do falante, numa cena evocada.

Do ponto de vista da forma, é importante destacar o tempo verbal de querer no primeiro segmento, que é um pretérito com função de futuro do pretérito, projetando o evento dentro do campo da possibilidade. Outro destaque é a utilização da oração adjetiva, "que eu faço letras", que serve para especificar e destacar a importância do $e u$ dentro da mensagem veiculada.

Toda essa leitura é possível por compartilharmos experiências e conhecimentos acerca do frame curso de letras. Podemos dizer que existe, no domínio do vocabulário, uma relação próxima entre o verbo volitivo querer e o focalizador contrastivo logo eu/tu. Ambos evocam uma projeção de valor semântico de futuridade, considerando-se o compartilhamento da cena geral (FILLMORE, 1977), que é o pertencimento à comunidade de letras.

(08) “Aí a pessoa queria me fazer de palhaça, logo eu, a dona do circo.” (Rede Social)

No exemplo (08), observamos dois segmentos: o primeiro aponta um falante/escrevente que deseja mostrar que haveria impossibilidade de o ouvinte cogitar alguma expectativa acerca de ela ser feita de palhaça, e o segundo representa a quebra de expectativa resultante de inferência, que desencadeia uma leitura de negação. O pareamento forma/sentido ocorre com uma oração 1 com verbo modalizador+ oração 2. LOGO X(no início) + sintagmas. Logo focaliza e eu refere-se a si mesmo, como referenciação ao locutor do discurso preenchido no slot. O sintagma nominal a dona do circo especifica formalmente quem é o representante $e u$.

No que se refere à função da construção, nota-se, no primeiro segmento, surpresa do locutor à tentativa de ser feita de palhaça. "A pessoa queria me fazer de palhaça" gera uma expectativa, que é negada por inferência, ou seja, não teve êxito: a pessoa queria me fazer de palhaça, mas não conseguiu. Uma observação importante é a presença de verbos volitivos explícitos que apontam pensamentos aceitos como expectativas, e o tempo verbal pretérito com leitura de futuro do pretérito que desencadeia expectativa, isto é, o desejo de que uma ação/estado se concretize.

No segundo segmento, há uma justificativa (sou a dona do circo) que representa a impossibilidade da realização da expectativa do segmento anterior. Tal justificativa se baseia em um frame. 
Portanto, a construção evoca um cenário compartilhado de que a expressão fazer de palhaça é utilizada quando acreditamos que o outro pode ser enganado ou quando se age de má fé, duvidando da capacidade do outro de entender sobre o que acontece. Desse modo, ser a dona do circo é a metaforização de saber mais que o palhaço e, portanto, a impossibilidade de ser enganada. Logo eu representa a manifestação da focalização do contraste entre o que é esperado anteriormente: a expectativa de fazer alguém de palhaça e o conhecimento compartilhado do frame do segundo segmento que leva a não realização dessa expectativa.

Assim, a desigualdade entre os segmentos tem a sua marca registrada no logo eu, como um focalizador contrastivo que chama a atenção da negação resultante da desigualdade, e aponta para a surpresa do falante/enunciador devido à expectativa do interlocutor de que a falante poderia ser feita de palhaça. Percebe-se o tom irônico ao se recorrer ao frame circo, numa linguagem metafórica, aproximando os elementos palhaço e circo (FILLMORE, 1982).

A seguir, um exemplo com a construção logo tu em que o contraste resulta em oposição negativa, com valor de decepção/frustração:

(09) A sister quer saber pra onde Marcos já foi e o cirurgião lista os lugares do Brasil e do mundo, mas confessa que não conhece Minas Gerais. A gaúcha fica surpresa e exclama: 'Que milagre! Logo tu, ariano, não conhece BH!'. 'Vou pra lá então‘, ele dispara. Em seguida vai até a jovem e a enche de beijinhos no rosto (site Globo.com).

No excerto (09), a situação comunicativa retratada no trecho é um diálogo entre participantes do reality show Big Brother Brasil enquanto estão no programa de televisão. O frame engloba inter-relação entre participantes sobre variedades, como num show ininterrupto. A sister (Emily) e o participante Marcos conversam sobre viagens e ele afirma que não conhece Belo Horizonte.

Emily se surpreende com a resposta do viajado Marcos e manifesta surpresa, perplexidade e frustração no primeiro segmento. Já, no segundo segmento, “Logo tu, ariano, não conhece BH”, ela quebra a expectativa gerada de que ele deveria conhecer Minas Gerais e afirma que o ouvinte não conhece BH. Neste segmento, temos o logo tu, em que o tu é destacado, pois é um recurso para se focalizar a surpresa dela. Temos aí a relação semântica contrastiva por oposição. Na crença criada pela participante, pode-se dizer que Emily "aplica um frame em uma determinada situação, mostrando que pretende fazê-lo, usando determinadas palavras, que devem ser reconhecidas como suporte em tal frame" (FILLMORE, 1977, p. 384). 
Nota-se que a crença criada pela participante considera o signo astrológico de Marcos como relevante, por ele ser do signo de áries. Tal conhecimento faz parte de determinado grupo social, ao saber que as pessoas desse signo valorizam aspectos físicos para um relacionamento amoroso, o que pode ser ou não compartilhado por todos os seus membros.

É interessante notar que o contexto contrastivo mostra-nos aspectos mais diretos da negação e da desigualdade. Não se percebe valor de futuridade, mas depreende-se não uma informação direta, mas que precisa ser inferida, o que é desencadeado por logo tu. Segundo Fillmore (op.cit., p. 384), “algumas vezes a perspectiva que é assinalada pela palavra não é a da cena corrente, mas alguma coisa que possa ser visível numa representação pictórica da cena".

\section{Conclusão}

As construções em foco apresentam relações semânticas contrastivas, sendo que o acontece que incorpora mais valores do mas, o que o coloca como membro mais próximo do centro da categoria de conectores contrastivos e o logo eu/tu instanciam apenas dois dos valores semânticos de mas, o que os coloca na margem da categoria de contraste. Ambas as construções são também recursos de focalização, sendo a primeira construção focalização de aspecto negativo. Das relações propostas por Neves (2011), encontramos:

Tabela 1 - Relação contrastiva e focalizadora de acontece que

\begin{tabular}{|l|l|}
\hline Contraste por oposição & 28 \\
\hline Contraste por parcialidade & 28 \\
\hline Contraste por negação de inferência & 26 \\
\hline Contraste por eliminação do trecho anterior & 23 \\
\hline Contraste por direção independente & 22 \\
\hline Contraste por marcação de compensação & 6 \\
\hline
\end{tabular}

Fonte: Elaboração própria, com base em Pacheco (2020).

Já em relação aos usos da construção $\operatorname{logo} e u / t u$, verificamos que o contraste é manifestado por negação de inferência e por oposição, conforme tabela 4.

Tabela 2 - Relação contrastiva e focalizadora de logo eu e logo tu

Fonte: Elaboração própria.

\begin{tabular}{|l|l|}
\hline Contraste por oposição & 4 \\
\hline Contraste por negação de inferência & 75 \\
\hline
\end{tabular}

Podemos confirmar que as novas construções fazem parte da categoria de contraste e que se apresentam como novos chunks criados pelo falante para mostrar também focalização. 
A focalização aponta para o contraste encontrado entre os dois segmentos, cabendo à primeira construção um tom mais negativo e à segunda, um tom de decepção e frustração. Quanto ao valor de tempo na base das construções, pode-se considerar que o tempo verbal presente, de valor atemporal, que engloba o momento da fala, aponta para um patamar argumentativo irrefutável, na primeira construção, mas há uma projeção de futuridade e de volição mais caracterizada na segunda construção.

\section{Referências}

ABRAÇADO, M. J. O tempo, o tempo linguístico e o tempo verbal. São Paulo: Contexto. 2020.

AZEREDO, J. C. Gramática Houaiss da língua portuguesa. São Paulo: Publifolha, 2010.

BALLY, C. Linguistique générale et linguistique française. 4. ed. Editions Francke Berne, 1965 [1944].

BYBEE, J. Língua, uso e cognição. Trad. Maria Angélica Furtado da Cunha. São Paulo: Cortez, 2016.

CASTILHO, A. T. de. Nova Gramática do Português Brasileiro. São Paulo: Editora Contexto. 2010.

CROFT, W. Radical construction grammar: syntactic theory in typological perspective. Oxford: Oxford University Press, 2001.

DIAS, N. Construções contrajuntivas não prototípicas em variedades da língua portuguesa. Relatório de pesquisa. UFF. 2020.

DIAS; CORREA. O valor contrajuntivo de acontece que. Revista Confluência. No prelo.

DIK, S. C. et al. On the typology of focus phenomena. In: HOEKSTRA, T. (Ed.).

Perspectives on Functional Grammar. Dordrecht: Foris, 1981. p. 41-74.

FILLMORE, C. Frame semantics. In ZAMPOLLI, A. (Ed.). Linguistic Structure Processing. Amsterdam: North Holland Publishing Company, 1977. p. 55-82.

GOLDBERG, A. Constructions: a construction grammar approach to argument structure. Chicago: University Press, 1995.

HALLIDAY, M. A. K. An introduction to functional grammar. 2. ed. London/New York: Arnold/Oxford University Press, 1994 [1985].

HILPERT, M. Constructional Change in English. Cambridge University Press, 2013.

HOPPER, P.; TRAUGOTT, E. C. Grammaticalization. Second Edition. Cambridge: Cambridge University Press, 2003. 
ILARI, R. Sobre advérbios focalizadores. In: Gramática do português falado. v. 2. Campinas: Ed. Unicamp/Fapesp, 1992. p. 193-212.

KORTMANN, B. Adverbial subordination: a typology and history of adverbial subordinators based on European languages. Berlin; New York: M. de Gruyter, 1996.

LAMBRECHT, K. Information structure and sentence form. A theory of topic, focus, and the mental representations of discourse referents. Cambridge: Cambridge University Press, Cambridge Studies in Linguistics, v. 71, 1994.

LANGACKER, R.W. Gramatical Traces of some "Invisible" Semantic Constructs. Language Sciences, p. 323-355, 1993.

LEITE DE OLIVEIRA, D. Construções de foco com o marcador "éto" em russo. Tese de doutorado. Rio de Janeiro: UFRJ, 2017.

LONGHIN, S.R. A gramaticalização da perifrase conjuncional 'só que'. Tese (doutorado) - Unicamp, Instituto de Estudos da Linguagem. Campinas, SP: [s.n.], 2002.

LIMA, G. Modelos de categorização: apresentando o modelo clássico e o modelo de protótipos. Perspectivas em Ciência da Informação, v. 15, n. 2, p. 108-122, 2010.

LYONs, J. Semântica II. Editorial Presença/Martins Fontes. Lisboa. 1977.

Memória Roda Viva. Iniciativa conjunta da Fundação Padre Anchieta, da Fundação de Apoio à Pesquisa do Estado de São Paulo (Fapesp) e da Universidade Estadual de Campinas (Unicamp). São Paulo. Disponível em: http://www.rodaviva.fapesp.b.

NEVES, M. H. M. O estatuto das chamadas conjunções coordenativas no sistema do português. Alfa, São Paulo, v. 29, p. 59-65, 1985.

NEVES, M. H. M. Gramática de usos do português. São Paulo: Editora UNESP, 2011.

PACHECO, P. H. A construção "acontece que" no português brasileiro contemporâneo: uma análise baseada no uso. 2020. Dissertação (Mestrado em Estudos da Linguagem) Programa de Pós-Graduação em Estudos de Linguagem, Universidade Federal Fluminense, Niterói. 2020.

PEZATTI, E.; THOMAZI, S. As construções coordenadas. In: ILARI, R.; NEVES, M. H. M. (Orgs.). Gramática do português culto falado no Brasil. v. 2. Campinas: Ed. Unicamp, 2008.

RAMOS, J. A construção LOGO X. Comunicação pessoal em Seminário Interno do Porus. Universidade Federal Fluminense, Niterói, 2019.

ROSH, E. Principles of categorization. In: ROSCH, E.; LLOYD, B. (Eds.). p. 27-48. 1978.

TAYLOR, John R. Linguistic categorization: prototypes in linguistic theory. New York: Oxford University Press, 1995. 
TRAUGOTT, E.; TROUSDALE, G. Construcionalization and constructional changes. Cambridge. Oxford. 2013.

\section{Sobre os autores}

Nilza Barrozo Dias (Orcid iD https://orcid.org/0000-0003-3521-508X)

Doutora em Linguística pela Universidade Estadual de Campinas (UNICAMP), com estágio doutoral na University of Santa Barbara; mestra em Letras pela Universidade Federal Fluminense (UFF); especialista em Língua Portuugesa pela UFF; licenciada em Letras - Português/Inglês pela Faculdade de Filosofia Santa Dorotéia. Realizou pósdoutorado na Universidade Católica Portuguesa. É professora do Instituto de Letras e do Programa de Pós-Graduação em Estudos de Linguagem da UFF.

Jocineia Andrade Ramos Araújo (Orcid iD: http://orcid.org/0000-0002-2839-6399) Doutoranda no Programa de Pós-Graduação em Estudos de Linguagem da Universidade Federal Fluminense (UFF); mestra em Estudos de Linguagem pela mesma instituição; graduada em Letras - Português/Literaturas pela UFF. É professora substituta do Instituto Federal de Educação, Ciência e Tecnologia do Rio de Janeiro e professora de Língua Portuguesa e Literatura na rede privada.

Priscilla Hoelz Pacheco (Orcid iD: https://orcid.org/0000-0002-1367-4114)

Doutoranda em Estudos de Linguagem pela Universidade Federal Fluminense (UFF); mestra em Estudos de Linguagem pela mesma instituição; graduada em Comunicação Social - Jornalismo e em Letras - Português/Inglês pela UFF. É Técnica em Assuntos Educacionais na Superintendência de Relações Internacionais da UFF.

Recebido em julho de 2020.

Aprovado em setembro de 2020. 